\title{
Rupatadine in Established Treatment Schemes Improves Chronic Spontaneous Urticaria Symptoms and Patients' Quality of Life: a Prospective, Non-interventional Trial
}

\author{
Martin Metz $\cdot$ Karsten Weller · Claudia Neumeister · Iñaki Izquierdo • \\ Rolf-Hasso Bödeker · Ulrich Schwantes · Marcus Maurer \\ To view enhanced content go to www.dermtherapy-open.com \\ Received: October 12, 2015 / Published online: November 21, 2015 \\ (C) The Author(s) 2015. This article is published with open access at Springerlink.com
}

\begin{abstract}
Introduction: Chronic spontaneous urticaria (CSU) is a common and hard to treat condition associated with a substantial negative impact on patients' quality of life (QoL). Clinical studies have shown that rupatadine is effective and safe in the treatment of CSU, but data from routine clinical care are scarce. Therefore, we assessed the effectiveness and tolerability of rupatadine

Electronic supplementary material The online version of this article (doi:10.1007/s13555-015-0089-y) contains supplementary material, which is available to authorized users.
\end{abstract}

M. Metz $\cdot$ K. Weller · M. Maurer

Department of Dermatology and Allergy,

Allergy-Centre-Charité, Charité-University Hospital

Berlin, Berlin, Germany

C. Neumeister · U. Schwantes $(\bowtie)$

Department of Medical Science/Clinical Research,

Dr. R. Pfleger GmbH, Bamberg, Germany

e-mail: ulrich.schwantes@dr-pfleger.de

I. Izquierdo

Department of Clinical Research, Uriach Group,

Barcelona, Spain

Rolf-HassoBödeker

Department of Statistics, Institute for Medical

Informatics, University Clinic Giessen, Giessen,

Germany in established dosages on CSU activity and patients' QoL in a routine daily practice setting. Methods: This was an open, prospective, non-interventional study performed in 146 dermatological practices in Germany. CSU patients for whom treatment with rupatadine was indicated were eligible to participate. Key symptoms of urticaria activity and their impact on patients' QoL were assessed at the beginning and the end of treatment. Adverse events (AEs) and withdrawals, as well as the dosage regimens chosen, were documented. Patients and physicians were requested to rate effectiveness and tolerability of therapy at the final visit. All statistical analyses were descriptive.

Results: The majority of the 660 patients screened to be treated (median age 44 years, IQR $=31-59$ years, $\quad n=654) \quad$ received rupatadine $10 \mathrm{mg}$ tablets once (477 patients) or twice (105 patients) daily for a median time of 28 days. After treatment, $93.2 \%$ of the patients (606/650) reported a clear overall improvement of symptoms. Rupatadine significantly reduced the urticaria activity score (UAS7) as well as the frequency and severity of existing angioedema episodes. Similarly all domains of the urticaria-specific 
QoL questionnaire $\left(\mathrm{CU}-\mathrm{Q}_{2} \mathrm{OL}\right)$ were markedly improved. The majority of physicians and patients rated rupatadine treatment as effective and well tolerated. There were 39 (5.9\%) early treatment withdrawals, and 21 patients (3.2\%) experienced AEs.

Conclusion: Rupatadine when given according to the routine treating schemes improves symptoms and $\mathrm{CU}-\mathrm{Q}_{2} \mathrm{OL}$ of CSU patients; the drug is also safe and well tolerated.

Funding: Dr. R. Pfleger GmbH.

Keywords: Angioedema; Chronic spontaneous urticaria (CSU); Chronic urticaria questionnaire on quality of life (CU-Q $\left.{ }_{2} \mathrm{OL}\right)$; Non-interventional study; Quality of life (QoL); Rupatadine; Urticaria activity score (UAS7)

\section{INTRODUCTION}

Chronic spontaneous urticaria (CSU) is one of the most common and disturbing cutaneous conditions. CSU is characterized by the daily or almost daily reoccurrence of pruritic wheals, angioedema, or both, for more than 6 weeks [1]. In the majority of cases, the underlying cause remains unidentified $[1,2]$. The condition often lasts for years $[1,2]$. Besides being bothersome and debilitating, CSU has a proven substantial negative impact on quality of life (QoL) of affected individuals [2-7]. Treatment, which is almost always provided on an outpatient basis, is still a challenge. The first line treatment of CSU, according to the recommendations of the current EAACI/GA ${ }^{2} \mathrm{LEN} / \mathrm{EDF} / \mathrm{WAO}$ urticaria guideline [1], is the continued use of non-sedating, second-generation antihistamines (nsAHs). These drugs have been shown to be efficacious and safe in numerous clinical trials, but real-life data from the use of these drugs in routine clinical care are limited.
This is especially true for newer nsAHs such as rupatadine.

Rupatadine, an $\mathrm{N}$-alkyl pyridine derivative, is a selective oral histamine $\mathrm{H}_{1}$-receptor inverse agonist, indicated for symptomatic treatment of allergic rhinitis and urticaria in adults and children $\geq 2$ years $[8,9]$. The drug exhibits strong and balanced antagonist activities towards both histamine $\mathrm{H}_{1^{-}}$and platelet-activating factor (PAF) receptors (for review see: [10-16]). Both histamine and PAF are held to importantly contribute to the signs and symptoms of CSU, i.e., itchy wheals and angioedema [17]. Moreover, rupatadine has a broad profile of anti-inflammatory effects by inhibiting both inflammatory cells and a range of mediators involved in the early- and late-phase inflammatory responses [10, 18, 19]. After oral administration, rupatadine shows a fast onset of action, producing rapid symptomatic relief, and a long-lasting ( $>24 \mathrm{~h}$ ) clinical activity, which allows administration once a day $[12,20]$. Rupatadine has undergone long-term testing (up to 1 year) in compliance with ICH and EMA guidelines confirming its good safety profile [21-23]. At the licensed daily oral dose of $10 \mathrm{mg}$, rupatadine has no clinically relevant effects on the cardiovascular system, cognitive function or psychomotor function $[10,14]$.

The current guideline on the management of urticaria patients recommends aiming for a complete symptom relief [1]. However, many patients fail to get satisfactory relief with the licensed doses $[1,2]$. In this case, the European guideline advises to progressively increase the conventional dosages of oral nsAHs up to fourfold in poorly responding patients [1]. In fact, higher doses of antihistamines are very common in general practice and in clinical studies and do show benefits for individual patients [1, 2, 21, 24]. However, there is little 
information on the use, the effects and safety of rupatadine in CSU treatment outside of RCTs neither for the approved nor for higher than standard doses. To address this gap of knowledge, we have assessed treatment responses to rupatadine administered according to current routine treatment schemes in a large and diverse population of CSU outpatients with a special focus on the effects of therapy on disease activity and health-related QoL impairment as well as tolerability.

\section{METHODS}

\section{Study Design}

This multicenter, open, prospective, non-interventional, observational trial was conducted by 146 dermatologists in private practices in Germany from April 1, 2011 until June 30, 2011 (last day of recruitment). The rupatadine therapy was prescribed by the participating physicians in the course of normal outpatient care, was commercially available and funded according to local practice in usual routine care. The study protocol, therefore, did not contain any specifications regarding dosing of rupatadine or duration of treatment. Instead, the advising dermatologists were asked to follow the recommendations defined in the licensed approval from the national regulatory authorities. The contraindications, special warnings and precautions for use, interactions, information on use during pregnancy and lactation, effects on ability to drive and use machines, and desirable effects specified in the Summary of Product Characteristics (SmPC) had to be observed. Prior to the start of this study, all participating physicians were instructed in the conduct and documentation of the trial.

\section{Compliance with Ethics}

This non-interventional, observational trial conformed with $\S 67(6)$ of the German Drug Law. Accordingly, the competent authorities, National Association of Statutory Health Insurance Physicians, and the central association of health insurers were given notice of the study. Approval of an ethical committee was not required for such a non-interventional post-registration trial in Germany. Nevertheless, the study protocol was submitted to the independent Freiburger Ethics Committee, Freiburg, Germany, who gave a favorable recommendation prior to the start of the study (February 2011). All procedures were carried out according to the established regulations and official recommendations of the Federal Institute for Drugs and Medical Devices (BfArM) and the Paul-Ehrlich-Institute (PEI) relating to the conduct of non-interventional trials [25]. This study was performed within the indication approved in the marketing authorization and under consideration of the contraindications and precautions defined there. Informed consent regarding data protection was obtained from all patients before being included in the study.

\section{Patients}

All outpatients with a confirmed diagnosis of CSU, for whom treatment with a second-generation $\mathrm{H}_{1}$-antihistamine was indicated and a rupatadine preparation containing $10 \mathrm{mg}$ active agent per tablet (e.g., Urtimed $^{\circledR} \quad 10 \mathrm{mg}$ Tabletten, Dr. R. Pfleger GmbH, Bamberg, Germany, [8]) was prescribed by the attending physician, were eligible to enter the trial. Any current and prior medications were acceptable for their inclusion. Participants were free to withdraw 
at will at any time. If they were or decided to withdraw from the study, the reason for discontinuation had to be specified.

The sample size of this trial was formed through the number of patients that were treated during the predetermined study period by any of the participating dermatologists.

\section{Assessments and Outcome Measures}

There were no defined study-related procedures; measurements were made by the treating physicians only as determined in the context of routine patient care. Thus, effectiveness and safety of therapy were assessed through measurements made at usual visits. Trial visits were defined as initial and final (around 4-10 weeks from baseline) visit. An observation form (CRF) was used to record the data gathered from every patient. The CRF at the initial visit included demography, medical history, suspected triggers, measures for confirmation of diagnosis, pre- and concomitant medications, prescribed dosage and duration of treatment with rupatadine tablets, the Urticaria Activity Score (UAS7) and the angioedema score, each of them generated over seven consecutive days. The UAS, recommended by the EAACI/GA ${ }^{2} \mathrm{LEN} / \mathrm{EDF} /$ WAO guideline, is a simple scoring system, which captures number of wheals, and intensity of pruritus $[1,5]$. Daily number of hives ratings [range: $0=$ none; $1=$ mild $(<20$ wheals $/ 24 \mathrm{~h})$; $2=$ moderate $(20-50$ wheals $/ 24 \mathrm{~h}) ; 3=$ intense ( $>50$ wheals/24 h or large confluent areas of wheals] and severity of itch [range: $0=$ none; $1=$ mild (present but not annoying or troublesome); 2 =moderate (troublesome but does not interfere with normal daily activity or sleep); 3 =intense (severe pruritus, which is sufficiently troublesome to interfere with normal daily activity or sleep] are summed up to create a daily UAS score (range: 0-6 points/day), the UAS7, that is, the sum score of seven consecutive days (maximum score of 42). Another measure of disease activity, the presence and size of a concurrent angioedema, was recorded on a scale ranging from $0=$ none to 3 =large, and its localization was documented (eyes, lips or other; free text entry). At final examination, the following had to be documented: actual treatment period and dosing of rupatadine, onset of efficacy, intended continuation of medication and dose, physician's and patient's assessment of treatment effectiveness and tolerability, any adverse drug effects as well as premature treatment termination, and again the UAS7 and the angioedema score.

Additionally, at the initial and final visit, the patients were asked to fill in the German version of the validated Chronic Urticaria Quality of Life Questionnaire (CU- $\left.\mathrm{Q}_{2} \mathrm{OL}\right)[3,6]$ to assess the impact of the disease on their quality of life. The

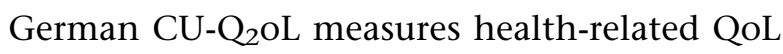
in 6 domains (functioning, sleep, itching/ embarrassment, mental status, swelling/eating, and limits looks) and comprises 23 items evaluating the answers on a five-level Likert scale.

\section{Data Management and Statistics}

Data were entered into a data base (MS ACCESS 2003) via single entry. The validity of data was checked (a) by plausibility checks within the data base and (b) by a comparison of all data with the data in $5 \%$ of all CRFs. Data were analyzed by the statistical program SPSS 10.0 (IBM Corporation, NY, USA) solely in an exploratory sense. Descriptive statistics were used to report the results. Analyses of all variables, including effectiveness and tolerability outcomes, were performed using 
any participant entered into the study who had the data relevant to that analysis. Distribution of each variable is presented by median, minimum, maximum, and interquartile range (IQR). As normal distribution of the parameters of interest could not be assumed, change from baseline UAS7 score and CU- $\mathrm{Q}_{2} \mathrm{OL}$ was analyzed using the Wilcoxon signed rank test. The given computed $p$ values for the observed or a more extreme result were $p<0.001$; the $p$ values are only a measure of the reproducibility of the observed results.

\section{RESULTS}

\section{Trial Population and Patient Baseline Characteristics}

The data of all 660 participants included in this study were entered into the safety analysis. According to the observational plan, one patient was excluded from the evaluation of efficacy due to a treatment period of less than 7 days, leaving 659 patients for the efficacy analysis set.

Out of the 660 patients, 422 (63.9\%) were females and 235 (35.6\%) were males, while for 3 subjects $(0.5 \%)$ respective information was missing. The median age of the patients was 44 years (range 9-92 years, IQR 31-59 years, $n=654)$, and the median body weight $73 \mathrm{~kg}$ (range 44-220 kg, IQR 65-82 kg, $n=657$ ).

In $59.6 \%(391 / 656)$ of the patients, urticaria symptoms occurred daily $(15.9 \%, 104 / 656)$ or almost daily (43.8\%, 287/656), whereas $40.4 \%$ (265/656) showed intermittent urticaria attacks. A concomitant angioedema was present in $22.1 \%$ $(133 / 601)$ of patients. The most frequently suspected triggering factors for urticaria signs and symptoms were stress (41.5\%), food and food additives (20\%), illnesses (15.8\%) and medication (12.9\%). Prior to enrolment in the study, $66.7 \%$
(440/658) of the patients had received one or more medications for their CSU; most frequently used drugs were cetirizine (37.5\%) and loratadine $(22.5 \%)$. In $68.9 \%$ of the patients, inefficacy was the reason for changing the medication to rupatadine, and tolerability problems accounted for $17.5 \%$ of all changes.

\section{Evaluation of Efficacy}

The final visit took place after a median time period of 35 days $\quad(\min =1$ day, $\max =139$ days; $n=639$ ) following the initial visit. The median actual treatment period documented at the final visit was 28 days $(\min =1$ day, $\max =129$ days; $n=638)$. In 508 patients (79.6\%), therapy lasted between 15 and 59 days: in $41.4 \%(264 / 638)$ between 29 and 59 days and in $38.2 \%(244 / 638)$ between 15 and 28 days; $13.6 \%(87 / 638)$ of the patients were treated between 7 and 14 days, 1.1\% (7/638) between 1 and 6 days, and 5.6\% over a period of $\geq 60$ days (missing data: $22 / 660$ ). In all, $77.9 \%$ (477/612) of the patients took rupatadine $10 \mathrm{mg}$ tablets once daily and $17.2 \%(105 / 612)$ took the study drug twice daily. A dose of $30 \mathrm{mg} /$ day received $3.4 \%(21 / 612)$ of the patients, and $1.5 \%(9 / 612)$ reported other dosing (missing data: 48/660). During treatment, 76\% (490/645) of the patients had maintained the prescribed dose, whereas $16.7 \%(108 / 645)$ had reduced and another 7.3\% (47/645) had increased their dose; eight patients dropped out. Regular administration of the drug was confirmed for 521 patients. Concomitant medication was negated for 565 patients and confirmed for 80 patients. Respective information was missing for 15 patients. The most commonly used drugs were corticosteroids $(n=43$, e.g., (methyl) prednisolone) and other antihistamines ( $n=18$, e.g., cetirizine, loratadine; ranitidine, 
cimetidine). For 19 patients concomitant medications for other conditions were recorded.

After treatment with 10 and $20 \mathrm{mg}$ rupatadine, respectively, an overall improvement of symptoms was reported by 606 out of 650 patients (93.2\%) and negated by only $44(6.8 \%)$ patients; for 10 individuals, including eight drop-outs, no data were available. The median time to change of symptoms was specified at 4 days ( $\min =1$ day, $\max =40$ days, $n=594)$.

Evaluating disease activity by use of the UAS7, rupatadine significantly reduced number of wheals and pruritus severity from a median value of $25.0(\mathrm{~min}=2.0, \max =42.0$, IQR 18.0-30.0, $n=632$ ) before treatment to 7.0 $(\min =0, \max =42.0$, IQR 2.0-14.0, $n=632)$ post-treatment (Fig. 1). The change from baseline in these key symptoms of CSU over the treatment period is in median 15.5 $(\min =-23.0, \quad \max =42.0, \quad \mathrm{IQR} \quad 9.0-22.0$, $n=622$, $\left.p_{\text {Wilcoxon signed rank test }}<0.001\right)$.

Under treatment with either 10 or $20 \mathrm{mg}$ rupatadine per day, improvements in the frequency and severity/size of an angioedema were observed. At the final visit, 81 (60.9\%) out of the initial affected patients showed a complete response (i.e., no angioedema) and 42 patients (31.6\%) reported clinically meaningful improvements in the occurrence and severity of episodes as documented by the angioedema score; three patients reported worsening of the still existing angioedema and nine patients reported new development of an angioedema.

Before rupatadine treatment, CSU patients showed major impairment of overall disease-related QoL (Fig. 2) as well as in all domains of QoL including sleep, itching/ embarrassment and mental status as measured by the $\mathrm{Cu}-\mathrm{Q}_{2} \mathrm{OL}$ (Table 1 ). Under rupatadine treatment QoL of CSU patients improved with reductions in all six domains of the questionnaire from baseline, even in the items I (functioning) and VI (limits looks). Regarding the median change in total $\mathrm{Cu}-\mathrm{Q}_{2} \mathrm{OL}$ score of 23.91 $(\min =-48.91, \max =88.04, \mathrm{IQR}=13.04-36.96$, $n=551)$, there was an indication of an important change ( $\left.p_{\text {Wilcoxon signed rank test }}<0.001\right)$.

\section{Global Assessment of Effectiveness and Tolerability}

According to the observational study protocol, the data of 651 patients/physicians were considered relevant for overall assessment of treatment effectiveness. Figure $3 \mathrm{a}$ depicts the results of this rating as recorded by the physicians and patients at the final visit. Most of the dermatologists $(558 / 643,86.8 \%)$ rated therapy outcome as complete response (328/643) or as significantly improved (230/643), compared with $4.5 \%(29 / 643)$ of the physicians who assessed symptom severity to be unchanged $(26 / 643)$ or worse $(3 / 643)$. The patient ratings of the global efficacy of treatment with rupatadine followed similar trends, with only $1.8 \%(12 / 648)$ of patients rated effectiveness of therapy to be poor. Similarly, a significantly greater number of patients (622/648, 96\%) assessed treatment outcome as very good (477/ $648)$ or good (145/648).

Tolerability of rupatadine treatment was rated as very good or good by $87.8 \%(572 / 651)$ of the physicians and by $95.7 \%(620 / 648)$ of the patients (Fig. 3b).

The question relating to therapy continuation with rupatadine was answered affirmatively for 367 out of 648 patients (56.6\%) and negated for 276 patients (42.6\%) by the physicians after the observational period. The standard recommended daily dose of $10 \mathrm{mg}$ of rupatadine was the most frequently prescribed dosage $(271 / 367,73.8 \%)$. 


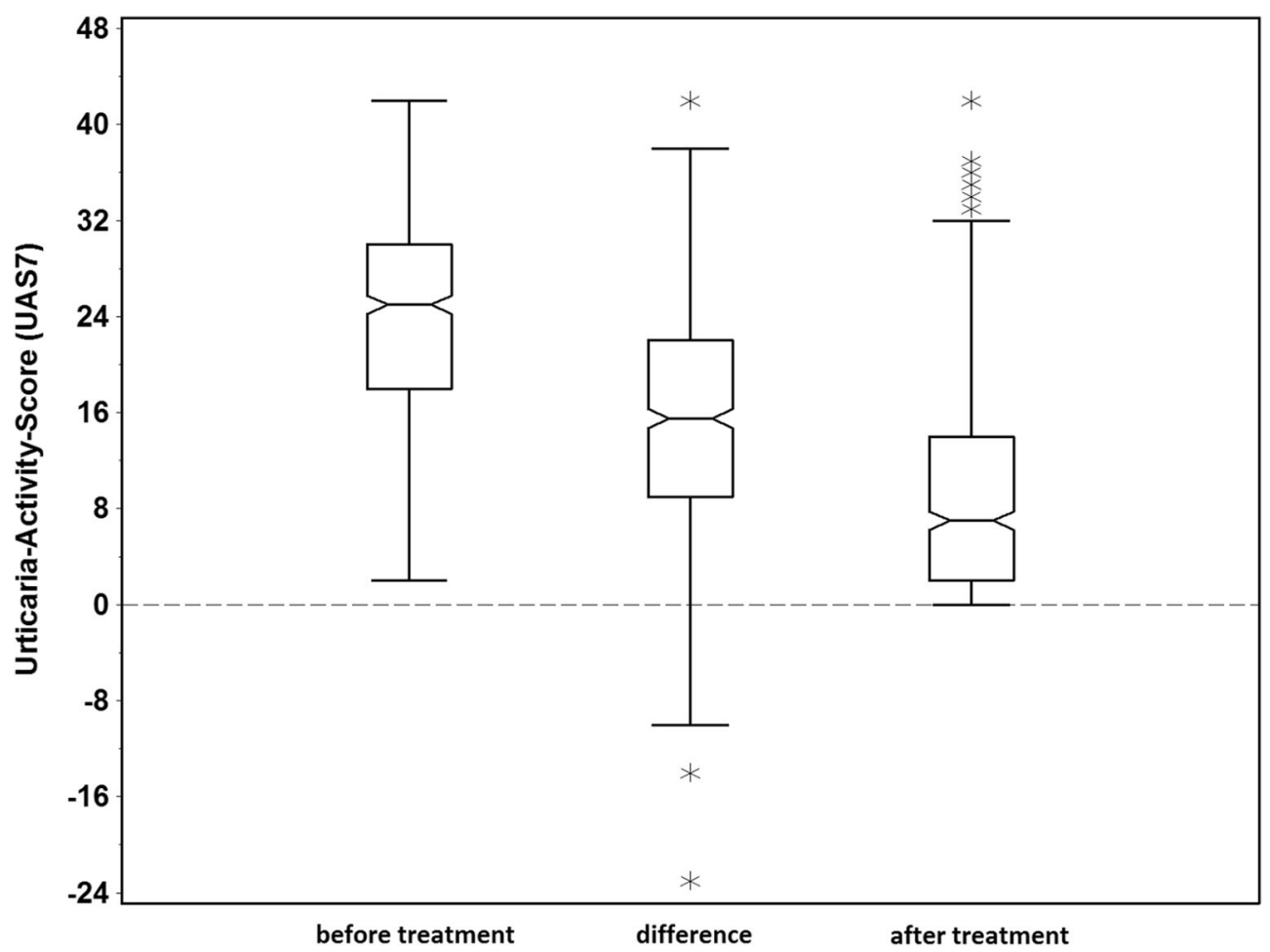

Fig. 1 UAS7 score before and after treatment with rupatadine $(n=622)$. The bottom and the top of each notched box are the first and third quartiles, and the line inside the box is the median. The whiskers represent the lowest extreme value limit still within $1.5 \times \mathrm{IQR}$ subtracted from the lower quartile, and the upper extreme value limit still within $1.5 \times \mathrm{IQR}$ added to the upper quartile. Stars mark extreme values which are either

\section{Therapy Withdrawals and Adverse Events}

Treatment with rupatadine was prematurely terminated in 39 out of 660 (5.9\%) patients. Reasons for withdrawal were lack of efficacy (20/ 39), AEs (7/39) and "other" (6/39) including 5 cases of nonattendance at the final visit, or not drug related (4/39); for 2 patients respective information was missing.

Overall, 21 out of the 660 (3.2\%) patients experienced 27 AEs during rupatadine treatment. The most frequently reported AEs with an at least possible causal relationship were fatigue $(n=11)$, headache $(n=3)$ and nausea $(n=3)$. Treatment with the study drug was
$1.5 \times \mathrm{IQR}$ or more above the third quartile or $1.5 \times \mathrm{IQR}$ or more below the first quartile, but which are not indicated as outliers. The notch around the median offers a rough approximation to the $95 \%$ confidence interval of the median. The computed $p$ value for the observed or a more extreme pre- versus post-treatment difference is $p<0.001$ (Wilcoxon signed rank test). IQR interquartile range

discontinued in 11 out of the 21 patients with an $\mathrm{AE}$, and in 10 cases medication was maintained.

\section{DISCUSSION}

To our knowledge this is the first observational, non-interventional study to demonstrate the effectiveness and favorable tolerability of oral rupatadine administered according to the established dosage recommendations in the treatment of CSU in routine outpatient care.

As CSU has a detrimental effect on both objective functioning and subjective well-being $[1,2,4-7,10]$, evaluation of urticaria activity is 


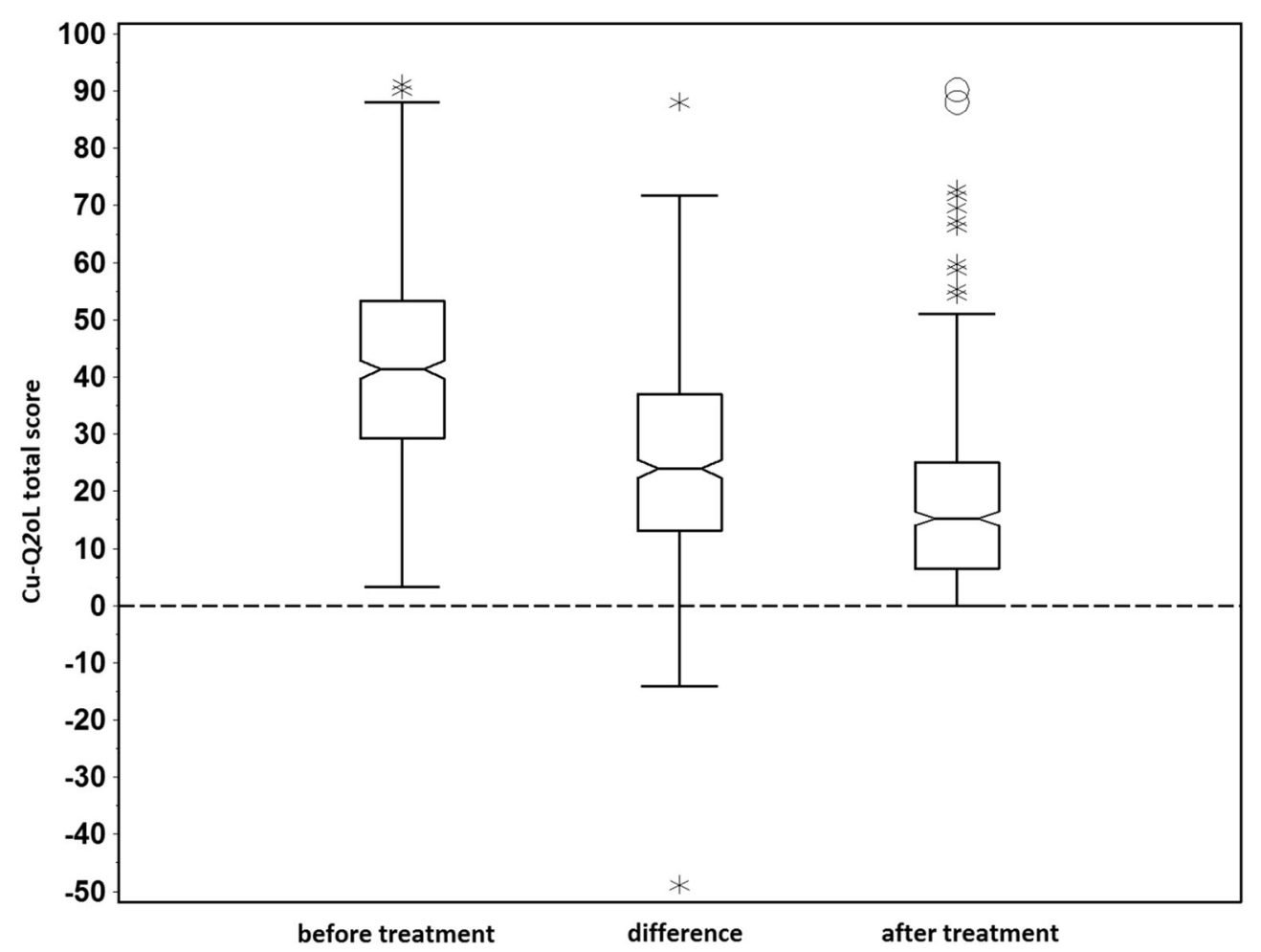

Fig. 2 CU- ${ }_{2} \mathrm{oL}$ total score before and after treatment with rupatadine $(n=521)$. The unfilled circles indicate outliers which are either $3 \times \mathrm{IQR}$ or more above the third quartile or $3 \times \mathrm{IQR}$ or more below the first quartile. The

just as important to be looked at as assessment of the impact of the disease on patients' QoL. Therefore, two validated and disease-specific tools for patient-reported outcomes assessment were used in the present study: the UAS7 score for symptoms and the $\mathrm{Cu}-\mathrm{Q}_{2} \mathrm{OL}$ questionnaire for urticaria-related QoL impairment. Noting the changes in frequency and severity of itchy wheals as well as of angioedema episodes is a useful way of evaluating clinical efficacy [1]. The relevant differences in CSU activity, observed in the present trial after a median treatment period of 28 days and determined through the use of the UAS7 and the angioedema score, indicated that an oral dose of $10 \mathrm{mg}$ rupatadine, administered once or twice daily, produced obvious improvements in the clinical status of the affected patients. computed $p$ value for the observed or a more extreme preand post-treatment difference was $p<0.001$ (Wilcoxon signed rank test). $C U-Q_{2} \circ L$ urticaria-specific QoL questionnaire, $I Q R$ interquartile range

These results are in line with the clinical evaluations, on which approval for the drug was granted. The efficacy of rupatadine in the treatment of moderate-to-severe CSU was evaluated in two randomized, double-blind, placebo-controlled multicentre studies [26, 27]. Both trials showed that rupatadine $10 \mathrm{mg}$ and $20 \mathrm{mg}$ per day rapidly and significantly reduced urticaria symptoms and improved health-related QoL of these patients. A pooled responder analysis of both studies highlighted the greater improvements when using the higher dosage of $20 \mathrm{mg}$ rupatadine daily [24]: evaluating disease activity by use of the UAS a significant reduction of at least $75 \%$ in the $10 \mathrm{mg}(34.8 \%)$ and $20 \mathrm{mg}$ (48\%) rupatadine groups as compared to $13.9 \%$ in the placebo group $(p<0.0001)$ was demonstrated. In the 
Table 1 Disease-specific quality of life impairment as assessed by the CU- ${ }_{2} \mathrm{oL}$ questionnaire before and at the end of treatment with rupatadine $10 \mathrm{mg}$ tablets, once or twice daily

\begin{tabular}{|c|c|c|c|c|c|c|}
\hline Item & $N$ & Minimum & Lower quartile & Median & Upper quartile & Maximum \\
\hline \multicolumn{7}{|l|}{ Functioning } \\
\hline Before treatment & 597 & 0.00 & 29.17 & 45.83 & 58.33 & 100.00 \\
\hline After treatment & 597 & 0.00 & 0.00 & 12.50 & 25.00 & 100.00 \\
\hline Difference $^{a}$ & 597 & -54.17 & 12.50 & 25.00 & 41.67 & 91.67 \\
\hline \multicolumn{7}{|l|}{ Sleep } \\
\hline Before treatment & 619 & 0.00 & 31.25 & 50.00 & 68.75 & 100.00 \\
\hline After treatment & 619 & 0.00 & 6.25 & 18.75 & 37.50 & 100.00 \\
\hline Difference $^{a}$ & 619 & -62.50 & 12.50 & 25.00 & 43.75 & 100.00 \\
\hline \multicolumn{7}{|c|}{ Itching/embarrassment } \\
\hline Before treatment & 617 & 0.00 & 43.75 & 56.25 & 68.75 & 100.00 \\
\hline After treatment & 617 & 0.00 & 6.25 & 18.75 & 31.25 & 100.00 \\
\hline Difference $^{\mathrm{a}}$ & 617 & -31.25 & 18.75 & 37.50 & 50.00 & 93.75 \\
\hline \multicolumn{7}{|l|}{ Swelling/eating } \\
\hline Before treatment & 604 & 0.00 & 6.25 & 18.75 & 37.50 & 87.50 \\
\hline After treatment & 604 & 0.00 & 0.00 & 6.25 & 12.50 & 93.75 \\
\hline Difference $^{\mathrm{a}}$ & 604 & -81.25 & 0.00 & 6.25 & 18.75 & 87.50 \\
\hline \multicolumn{7}{|l|}{ Mental status } \\
\hline Before treatment & 628 & 0.00 & 25.00 & 41.67 & 66.67 & 100.00 \\
\hline After treatment & 628 & 0.00 & 0.00 & 16.67 & 33.33 & 100.00 \\
\hline Difference $^{\mathrm{a}}$ & 628 & -50.00 & 8.33 & 25.00 & 41.67 & 100.00 \\
\hline \multicolumn{7}{|l|}{ Limits looks } \\
\hline Before treatment & 622 & 0.00 & 0.00 & 25.00 & 50.00 & 100.00 \\
\hline After treatment & 622 & 0.00 & 0.00 & 0.00 & 25.00 & 100.00 \\
\hline Difference $^{\mathrm{a}}$ & 622 & -75.00 & 0.00 & 12.50 & 25.00 & 100.00 \\
\hline
\end{tabular}

$C U-Q_{2} \circ L$ urticaria-specific QoL questionnaire

${ }^{a}$ Before treatment minus after treatment

present trial, the reduction in the UAS7 score evaluated for the change of the median values from baseline over the treatment period

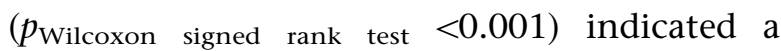
relevant therapeutic success. Moreover, the effects of rupatadine treatment seem at least similar when comparing its efficacy in clinical trials and a real-life setting.

The majority of the patients in our study (77.9\%) were using the approved (standard) dose of the drug (10 $\mathrm{mg}$ of rupatadine once daily) which is defined in the current SmPC [8]. 
A
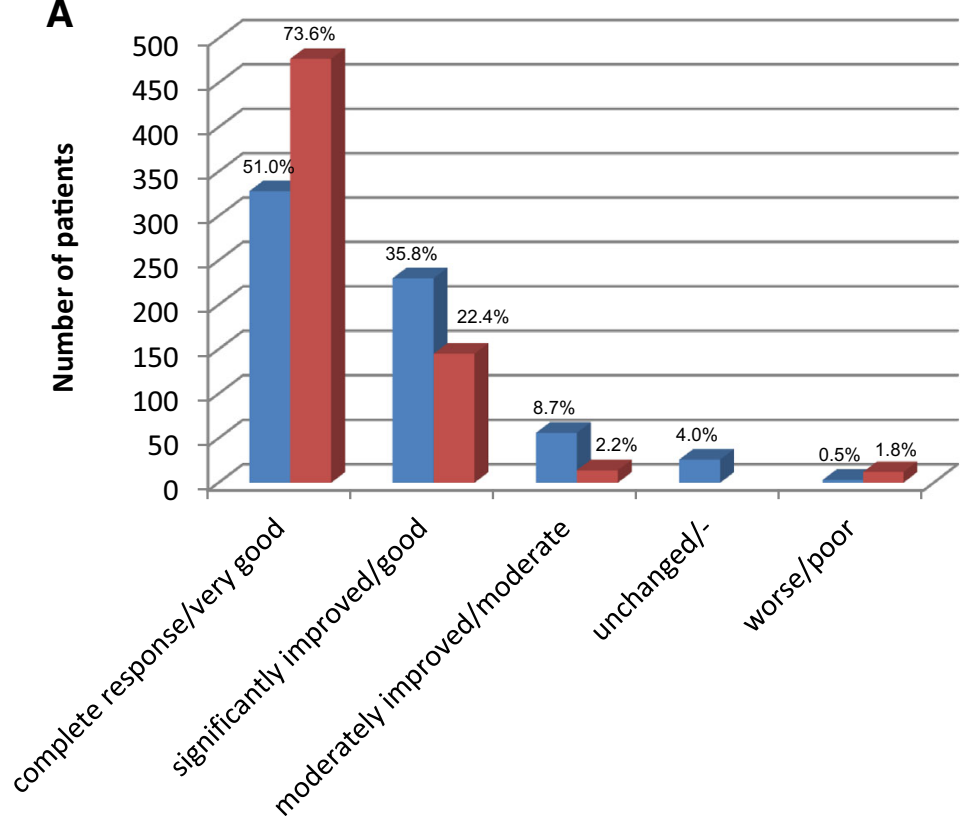

Rating categories (physicians/patients)

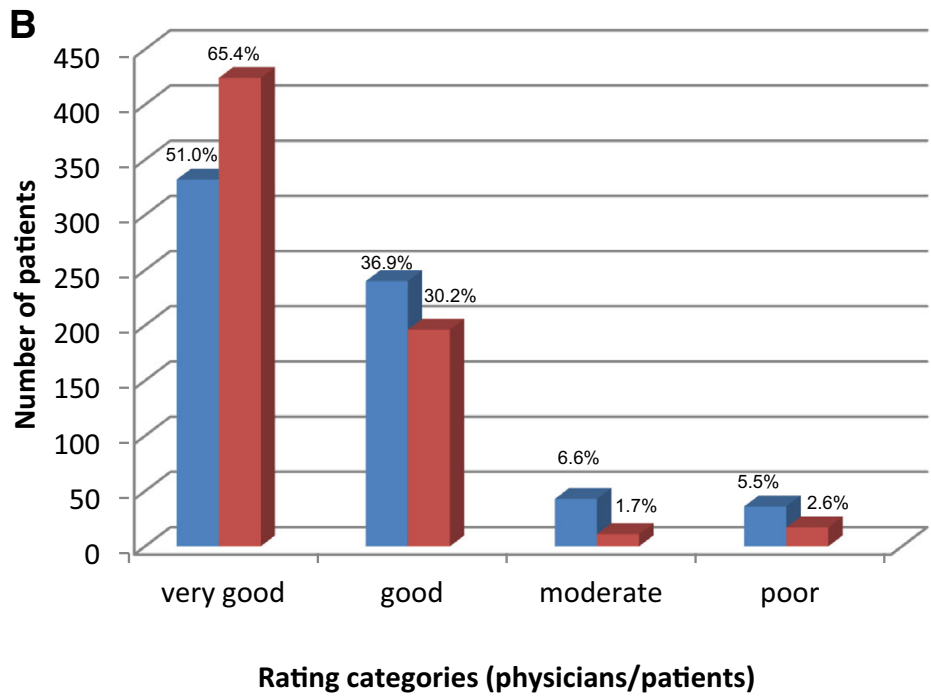

ahysicians $(\mathrm{n}=643)$

patients $(n=648)$ a physicians $(\mathrm{n}=651)$

a patients $(n=648)$

Fig. 3 Physicians' and patients' global assessment of treatment effectiveness a and tolerability $\mathbf{b}$ of rupatadine $10 \mathrm{mg}$ tablets, once or twice daily, at the end of treatment

Thus, the observed clinical benefits confirmed that the approved licensed dosage regimen was adequate for most patients. However, the non-predetermined dosing strategy allowed in the present trial reflects real-life use, and permitted treatment to be tailored to patients' individual needs, based on their individual responses to the drug. About $17.2 \%$ of the patients took the higher dosage of $20 \mathrm{mg}$ rupatadine per day. During treatment, most patients (76\%) maintained the prescribed dose, whereas only $7.3 \%$ increased and about $16.7 \%$ 
reduced it. This also demonstrates that a daily dose of 10 and $20 \mathrm{mg}$, respectively, of rupatadine successfully managed the symptoms of urticaria under everyday practice conditions.

Based on the favorable effectiveness observed in the present study, the responder rates to rupatadine treatment under real-life conditions might be higher than those expected for nsAHs. A systematic review of responder rates reported in RCTs indicated that $\mathrm{H}_{1}$-antihistamines relieve urticaria symptoms effectively only in $<50 \%$ of CSU patients [2].

The clinical benefits observed in our trial were mirrored by pronounced improvements in all domains of the $\mathrm{CU}-\mathrm{Q}_{2} \mathrm{OL}$ recorded in the study population. CSU patients are known to exhibit severely impaired QoL, and our results confirm this: disease-specific overall QoL was markedly reduced as assessed by the $\mathrm{CU}-\mathrm{Q}_{2} \mathrm{OL}$ questionnaire. Regarding the analysis of the six different domains of the $\mathrm{CU}-\mathrm{Q}_{2} \mathrm{OL}$, the changes in all domains can be regarded as meaningful to patients and indicate clinically relevant improvements in QoL. With regard to the $\mathrm{CU}-\mathrm{Q}_{2} \mathrm{OL}$ total score, the median change was evaluated as important ( $p_{\text {Wilxocon signed rank test }}$ $<0.001)$. Thus, rupatadine treatment in the established schemes is suitable to reduce the burden of recurrent CSU episodes in those patients. In previous studies, it was shown that rupatadine was even more effective than desloratadine, cetirizine and levocetirizine with regard to both, benefits in clinical outcome and patients' QoL [28-30].

The study drug was safe as demonstrated by a low frequency of AEs and only few withdrawals. All observed AEs with an at least causal relationship were well-known side effects of oral rupatadine [8]. In general, rupatadine treatment was well tolerated which is reflected by the subjective assessments of patients and physicians. The favorable tolerability of rupatadine at oral doses of 10 and $20 \mathrm{mg}$ daily has been evidenced in several clinical studies (reviewed by [10-16]). The most commonly reported AEs were somnolence (9.5\%), headache $(6.9 \%)$ and fatigue (3.2\%) (percentages of AEs according to [8]). The majority of AEs related to rupatadine were of mild or moderate severity and their incidence has been similar to those of active comparators or placebo. The good tolerability of rupatadine was confirmed in various long-term safety studies as well [21-23]. Most importantly, rupatadine has been shown to have no effects on CNS activity, on objective psychomotor tasks or on subjective evaluations [31-34], and has no cardiotoxic effects [35]. In two clinical studies, it has been demonstrated that the drug displays unwanted CNS side activities only at the highest evaluated dose of $80 \mathrm{mg}$, while therapeutically relevant lower doses (20 and $10 \mathrm{mg}$ ) were similar to placebo [31, 36].

Limitations of the current trial are dictated by the nature of an open, non-interventional study design, which follows national regulations and recommendations. For example, the heterogeneity of patients, the variable dosage regimen and lack of a control group limited relevance of study results, but in particular the first two parameters are representative of outpatient routine care. Thus, on the plus side, the open observational scenario highly reflects common use of the study drug in real-life clinical practice of a well-defined and sizable patient population treated at multiple sites. Moreover, the validated instruments, the UAS7 and the $\mathrm{CU}-\mathrm{Q}_{2} \mathrm{OL}$, used in the current trial cover relevant aspects of disease activity and health status; they are specifically standardized for global comprehensive assessment of CSU and thus, for monitoring treatment efficacy. In this sense, observational trials serve to verify the 
magnitude of previously reported clinical results. However, one interesting question arising out of the study results remains unanswered: What was the reason for the prescription of a higher dosage regimen for some patients?

\section{CONCLUSION}

This non-interventional trial confirmed oral rupatadine to be an efficacious and safe therapy option in patients with CSU. During treatment with this second-generation $\mathrm{H}_{1}$-antihistamine, symptoms of CSU and patients' QoL improved, as measured using validated and standardized instruments. The results suggest that the established and currently recommended treatment regimen is adequate for most patients.

\section{ACKNOWLEDGMENTS}

Sponsorship and article processing charges for this study were funded by Dr. R. Pfleger $\mathrm{GmbH}$, Bamberg, Germany. All named authors meet the International Committee of Medical Journal Editors (ICMJE) criteria for authorship for this manuscript, take responsibility for the integrity of the work as a whole, and have given final approval to the version to be published.

Editorial assistance in the preparation of this manuscript was provided by Dr. Petra Schwantes, BioMedical Services, Germany. Support for this assistance was funded by Dr. R. Pfleger GmbH.

Disclosures. M. Metz received honoraria as a speaker for Bayer, Dr. R. Pfleger, GSK, LEO, Sanofi, Shire, Moxie, MSD, Novartis, UCB, Uriach.
$\mathrm{K}$. Weller is or recently was a speaker for Dr. R. Pfleger, Uriach, UCB, Essex pharma (now MSD), Novartis, Shire, Vivopharma, and Moxie. In addition, he is or was involved in clinical research projects of Dr. R. Pfleger, Uriach, Essex pharma (now MSD), Novartis, Shire, and Vivopharma.

C. Neumeister is employee (Senior Project Manager Clinical Research) of Dr. R. Pfleger $\mathrm{GmbH}$.

I. Izquierdo is executive employee (Head Clinical Development \& Medical Advice) of Uriach Group.

R.-H. Bödeker is paid consultant (statistical planning and analysis) to Dr. R. Pfleger GmbH.

$\mathrm{U}$. Schwantes is executive employee (Head of Medical Science/Clinical Research) of Dr. R. Pfleger GmbH.

M. Maurer is or recently was a Speaker and/or Advisor for and/or has received funding from FAES, Genentech, GSK, Merckle Recordati, Novartis, Dr. R. Pfleger, Sanofi Aventis, MSD, UCB, and Uriach.

Compliance with ethics guidelines. All procedures followed were in accordance with the ethical standards of the independent Freiburger Ethics Committee, with the German Drug Law, and with the joint recommendations of the Federal Institute for Drugs and Medical Devices (BfArM) and the Paul-Ehrlich-Institute relating to the conduct of non-interventional trials. Informed consent regarding data protection was obtained from all patients before being included in the study.

Open Access. This article is distributed under the terms of the Creative Commons Attribution-NonCommercial 4.0 International License (http://creativecommons.org/licenses/ by-nc/4.0/), which permits any 
noncommercial use, distribution, and reproduction in any medium, provided you give appropriate credit to the original author(s) and the source, provide a link to the Creative Commons license, and indicate if changes were made.

\section{REFERENCES}

1. Zuberbier T, Aberer W, Asero R, et al. The EAACI GA2LEN, EDF, WAO guideline for the definition, classification, diagnosis, and management of urticaria: the 2013 revision and update. Allergy. 2014. doi:10.1111/all.12313.

2. Maurer M, Weller $\mathrm{K}$, Bindslev-Jensen $\mathrm{C}$, et al. Unmet clinical needs in chronic spontaneous urticaria. A Ga ${ }^{2} \mathrm{LEN}$ task force report ${ }^{1}$. Allergy. 2011;66:317-30.

3. Mlynek A, Magerl M, Hanna M, et al. The German version of the chronic urticaria quality-of-life questionnaire: factor analysis, validation, and initial clinical findings. Allergy. 2009;64:927-36.

4. Maurer M, Ortonne JP, Zuberbier T. Chronic urticaria: an internet survey of health behaviours, symptom patterns and treatment needs in European adult patients. BJD. 2009;160:633-41.

5. Mlynek A, Zalewska-Janowska A, Martus P, Staubach P, Zuberbier T, Maurer M. How to assess disease activity in patients with chronic urticaria. Allergy. 2008;63:777-80.

6. Baiardini I, Pasquali M, Braido F, et al. A new tool to evaluate the impact of chronic urticaria on quality of life: chronic urticaria quality of life questionnaire (CU-Q2OL). Allergy. 2005;60:1073-8.

7. Baiardini I, Braido F, Bindslev-Jensen C, et al. Recommendations for assessing patient-reported outcomes and health-related quality of life in patients with urticaria: a Ga ${ }^{2} \mathrm{LEN}$ taskforce position paper. Allergy. 2011;66:840-4.

8. Fachinformation (SmPC). Urtimed ${ }^{\circledR} 10 \mathrm{mg}$ Tabletten. Dr. R. Pfleger GmbH 2015. http://www.fachinfo.de.

9. Fachinformation (SmPC). Urtimed $^{\circledR} \quad 1 \mathrm{mg} / \mathrm{ml}$ Lösung. Dr. R. Pfleger 2014. http://www.fachinfo.de.

10. Mullol J, Bousquet J, Bachert C, et al. Update on rupatadine in the management of allergic disorders. Allergy. 2014;70:1-24.
11. Merlos M, Giral M, Balsa D, et al. Rupatadine, a new potent, orally active dual antagonist of histamine and platelet-activating factor (PAF). J Pharmacol Exp Ther. 1997;280:114-21.

12. Izquierdo I, Merlos $\mathrm{M}$, García-Rafanell J. Rupatadine. A new selective histamine $\mathrm{H}_{1}$ receptor and platelet-activating factor (PAF) antagonist. Drugs Today 2003;39(6):451-68.

13. Picado C. Rupatadine: pharmacological profile and its use in the treatment of allergic disorders. Expert Opin Pharmacother. 2006;7(14):1989-2001.

14. Keam SJ, Plosker GL. Rupatadine. A review of its use in the management of allergic disorders. Drugs. 2007;67(3):457-74.

15. Metz M, Maurer M. Rupatadine for the treatment of allergic rhinitis and urticaria. Expert Rev Clin Immunol. 2011;7(1):15-20.

16. Nettis E, Donne PD, Di leo E, Calogiuri GF, Ferrannini A, Vacca A. Rupatadine for the treatment of urticaria. Expert Opin Pharmacother. 2013;14(13):1807-13.

17. Krause K, Giménez-Arnau A, Martinez-Escala E, et al. Platelet-activating factor (PAF) induces wheal and flare skin reactions independent of mast cell degranulation. Allergy. 2013;68:256-8.

18. Queralt M, Brazís P, Merlos M, de Mora F, Puigdemont A. In vitro inhibitory effect of rupatadine on histamine and TNF- $\alpha$ release from dispersed canine skin mast cells and the human mast cell line HMC-1. Inflamm Res. 2000;49:355-60.

19. Vasiadi M, Kalogeromitros D, Kempuraj D, et al. Rupatadine inhibits proinflammatory mediator secretion from human mast cells triggered by different stimuli. Int Arch Allergy Immunol. 2010;151:38-45.

20. Peña J, Carbo M, Solans A, Nadal T, Izquierdo I, Merlos M. Antihistaminic effects of rupatadine and PKPD modelling. Eur J Drug Metabol Pharmacokinet. 2008;33(2):107-16.

21. Metz M, Scholz E, Ferrán M, Izquierdo I, Giménez-Arnau A, Maurer M. Rupatadine and its effects on symptom control, stimulation time, and temperature thresholds in patients with acquired cold urticaria. Ann Allergy Asthma Immunol. 2010;104:86-92.

22. Valero A, de la Torre F, Castillo JA, et al. Safety of rupatadine administered over a period of 1 year in the treatment of persistent allergic rhinitis. Drug Saf. 2009;32(1):33-42. 
23. Martinez-Escala M, Curto-Barredo L, Carnero L, Pujol RM, Giménez-Arnau A. Temperature thresholds in assessment of the clinical course of acquired cold contact urticaria: a prospective observational one-year study. Acta Derm Venerol. 2015;95:278-82.

24. Giménez-Arnau A, Izquierdo I, Maurer M. The use of a responder analysis to identify clinically meaningful differences in chronic urticaria patients following placebo-controlled treatment with rupatadine 10 and $20 \mathrm{mg}$. JEADV. 2009;23:1088-91.

25. BfArM 2010. Empfehlungen des Bundesinstituts für Arzneimittel und Medizinprodukte und des Paul-Ehrlich-Instituts zur Planung, Durchführung und Auswertung von Anwendungsbeobachtungen. http://www.bfarm.de/SharedDocs/Bekanntmachun gen/DE/Arzneimittel/klinPr/bm-KlinPr-20100707NichtinterventePr-pdf.pdf?_blob=publicationFile\& $\mathrm{v}=5$. Accessed 24 Jan 2011.

26. Dubertret L, Zalupca L, Cristodoulo T, et al. Once-daily rupatadine improves the symptoms of chronic idiopathic urticaria: a randomised, double-blind, placebo-controlled study. Eur J Dermatol. 2007;17(3):223-8.

27. Giménez-Arnau A, Pujol RM, Ianosi S, et al. Rupatadine in the treatment of chronic idiopathic urticaria: a double-blind, randomized, placebo-controlled multicentre study. Allergy. 2007;62:539-46.

28. Dakhale GN, Shinde AT, Mahatme MS, et al. Clinical effectiveness and safety of cetirizine versus rupatadine in chronic spontaneous urticaria: a randomized, double-blind, 6-week trial. Int J Dermatol. 2014;53:643-9.

29. Maiti R, Jaida J, Raghavendra BN, Goud P, Ahmed I, Palani A. Rupatadine and levocetirizine in chronic idiopathic urticaria: a comparative study of efficacy and safety. J Drugs Dermatol. 2011;10(12):1444-50.
30. Kolasani BP, Mudium R, Reddy N. A comparative study of efficacy and safety of rupatadine versus desloratadine in patients with chronic idiopathic urticaria. Asian J Biomed Pharm Sci. 2013;3(21):42-7.

31. Barbanoj MJ, García-Gea C, Morte A, Izquierdo I, Pérez I, Jané F. Central and peripheral evaluation of rupatadine, a new antihistamine/platelet-activating factor antagonist, at different doses in healthy volunteers. Neuropsychobiology. 2004;50:311-21.

32. Barbanoj MJ, García-Gea C, Antonijoan R, et al. Evaluation of the cognitive, psychomotor and pharmacokinetic profiles of rupatadine, hydroxyzine and cetirizine, in combination with alcohol, in healthy volunteers. Hum Psychopharmacol Clin Exp. 2006;21:13-26.

33. Vuurman E, Theunissen E, van Oers A, van Leeuwen C, Jolles J. Lack of effects between rupatadine $10 \mathrm{mg}$ and placebo on actual driving performance of healthy volunteers. Hum Psychopharmacol Clin Exp. 2007;22:289-97.

34. García-Gea C, Ballester MR, Martínez J, et al. Rupatadine does not potentiate the CNS depressant effects of lorazepam: randomized, double-blind, crossover, repeated dose, placebo-controlled study. Br J Clin Pharmacol. 2010;69(6):663-74.

35. Donado E, Izquierdo I, Pérez I, et al. No cardiac effects of therapeutic and supratherapeutic doses of rupatadine: results from a thorough QT/QTc study performed according to ICH guidelines. Br J Clin Pharmacol. 2010;69(4):401-10.

36. Church MK. Efficacy and tolerability of rupatadine at four times the recommended dose against histamine- and platelet-activating factor-induced flare responses and ex vivo platelet aggregation in healthy males. Br J Dermatol. 2010;163:1330-2. 